\title{
ESTUDO ANATÔMICO DO LENHO DE PSIDIUM CATTLEIANUM SABINE (MYRTACEAE) $^{1}$
}

\author{
JOSÉ NEWTON CARDOSO MARCHIORI² SIDINEI RODRIGUES DOS SANTOS ${ }^{3}$
}

\section{RESUMO}

O presente estudo fornece a descrição microscópica do lenho de Psidium cattleianum Sabine, com base em material proveniente do Rio Grande do Sul e Paraná (Brasil). As características anatômicas da madeira estão de acordo com as possibilidades estruturais para a família Myrtaceae e gênero Psidium, salientando-se, para a identificação da espécie: o comprimento de elementos vasculares $(809 \mu \mathrm{m})$ e de fibras $(1570 \mu \mathrm{m})$, a presença muito abundante de raios fusionados, de cristais solitários ou em séries curtas (até 3 unidades), e de poros solitários e em múltiplos radiais.

Palavras-chave: Psidium cattleianum, anatomia da madeira, Myrtaceae.

\section{ABSTRACT}

[Wood anatomy of Psidium cattleianum Sabine (Myrtaceae)].

This paper describes the microscopic wood anatomy of Psidium cattleianum Sabine, based on material from de states of Rio Grande do Sul and Paraná (Brazil). The anatomical features are according with literature references to family Myrtaceae and genus Psidium, being of special importance: the vessel and fiber length (809 and $1570 \mu \mathrm{m}$, respectively), the abundance of fusionated rays, single crystals and short crystalliferous strands (up to 3 units), as well as solitary and radial multiple vessels.

Key words: Psidium cattleianum, wood anatomy, Myrtaceae.

\section{INTRODUÇÃO}

Árvore pequena (até $6 \mathrm{~m}$ de altura), de copa globosa e casca lisa, castanho-avermelhada, Psidium cattleianum apresenta folhas obovadas (60 - 70 × $30-40 \mathrm{~mm})$, glabras e discolores, com face adaxial verde brilhante. Para separar a espécie de outros cinco Psidium nativos no Estado, salientam-se, ainda, o comprimento dos pecíolos $(5-7 \mathrm{~mm})$ e a abertura irregular do cálice na antese (Sobral, 2003). Os frutos de Psidium cattleianum, amarelos quando madu-

1 Recebido para publicação em 16/06/2009 e aceito para publicação em 10/07/2009.

2 Engenheiro Florestal, Dr., bolsista de Produtividade em Pesquisa ( $\mathrm{CNPq}$ - Brasil), Professor Titular do Departamento de Ciências Florestais, Universidade Federal de Santa Maria, Santa Maria, RS, Brasil. balduinia@mail.ufsm.br

3 Biólogo, bolsista (CNPq-Brasil), doutorando do Programa de Pós-Graduação em Engenharia Florestal, Departamento de Ciências Florestais, Universidade Federal de Santa Maria, CEP 97105-900, Santa Maria, RS, Brasil.sthurt.bio@gmail.com ros e de cálice persistente, assemelham-se a pequenas goiabas e são muito apreciados "in natura", bem como para fabricação de doces e geléias (Marchiori \& Sobral, 1997).

As características morfológicas, aliadas à facilidade com que se adapta a diversos tipos de solo e clima, tornam a espécie muito valorizada para ornamentação de praças e jardins. Além de ornamental e frutífera, produz madeira útil à construção civil, ou para dormentes, moirões, cabos de ferramentas e lenha. A respeito da madeira, aliás, Marchiori \& Sobral (1997) informam ser muito pesada, compacta, elástica, resistente e bastante durável.

Popularmente conhecida por araçá, Psidium cattleianum distribui-se de São Paulo ao Rio Grande do Sul; neste Estado, ocorre naturalmente na Floresta Atlântica e, por vezes, na Depressão Central (Sobral, 2003).

O presente estudo, ao descrever a anatomia da madeira de Psidium cattleianum, visa a contribuir para o conhecimento estrutural das Mirtáceas nativas no Rio Grande do Sul. 


\section{REVISÃO DE LITERATURA}

São muito escassas as informações sobre o gênero Psidium, no tocante à estrutura de suas madeiras, à semelhança do observado para o conjunto das Mirtáceas.

Em estudo anatômico-ecológico do lenho de Psidium cattleianum, Souza (2000) destaca, entre outros aspectos: anéis de crescimento distintos; porosidade difusa; vasos solitários, menos comumente em múltiplos radiais de $2-4$; poros com $63 \mu \mathrm{m}$ de diâmetro médio e freqüência de $33 / \mathrm{mm}^{2}$; elementos vasculares com placas de perfuração simples e pontoações intervasculares alternas; parênquima axial difuso-em-agregados, com cristais raros a abundantes; raios heterogêneos, com $1-2$ células de largura e $1-23$ células de altura, por vezes incluindo células perfuradas; fibras de $1586 \mu \mathrm{m}$ de comprimento, com pontoações areoladas e paredes espessas a muito espessas; além da presença de traqueídeos perivasculares.

Para o gênero Psidium, Metcalfe \& Chalk (1972) relacionam: poros solitários, pequenos a muito pequenos $(<100 \mu \mathrm{m})$, variando de $5-$ 20 , mas até mais de $100 / \mathrm{mm}^{2}$; elementos vasculares de comprimento médio (300 - 800 $\mu \mathrm{m})$, com placas de perfuração simples e pontoações intervasculares alternas, ornamentadas; parênquima axial inteiramente ou predominantemente apotraqueal e cristalífero, com câmaras por vezes distendidas; raios heterogêneos, em número inferior a $13 / \mathrm{mm}$, com menos de $1 \mathrm{~mm}$ de altura, 2 - 3 células de largura e $4-10$ (por vezes $1-3$ ) fileiras marginais de células quadradas e eretas; e fibras de $700-2000 \mu \mathrm{m}$ de comprimento, com pontoaçoes areoladas e paredes moderadamente a muito espessas.

\section{MATERIAL E MÉTODOS}

Para descrição anatômica, foram coletadas duas amostras de madeira nos municípios de Santa Maria (RS) e Curitiba (PR). O material lenhoso e respectivas exsicatas botânicas foram incorporados à Xiloteca e Herbário do Departamento de Ciências Florestais da Universida- de Federal de Santa Maria (HDCF), sob os números 5912 e 3167.

Das amostras de madeira, foram extraídos três corpos de prova $(1 \times 2 \times 3 \mathrm{~cm})$ da parte mais externa do lenho, próxima ao câmbio, orientados para obtenção de cortes nos planos transversal, longitudinal radial e longitudinal tangencial. Outro bloquinho foi também retirado, com vistas à maceração.

No preparo das lâminas de cortes anatômicos seguiu-se a técnica padrão no Laboratório de Anatomia da Madeira da Universidade Federal do Paraná: as amostras foram amolecidas por fervura em água e seccionadas em micrótomo de deslizamento, regulado para a obtenção de cortes com espessura nominal de $20 \mu \mathrm{m}$. Os cortes foram tingidos com acridina-vermelha, crisoidina e azul-de-astra (Dujardin, 1964), desidratados em série alcoólica-ascendente $(30 \%$, $50 \%, 70 \%, 95 \%$ e duas vezes em álcool absoluto), diafanizados em xilol e montados em lâminas permanentes, com Entellan.

Para a confecção de lâminas de macerado, usou-se o método de Jeffrey (Burger \& Richter, 1991), coloração da pasta com safranina 1\% e montagem permanente, com Entellan.

A descrição microscópica da madeira baseou-se nas recomendações do IAWA Committee (1989). No caso da percentagem dos tecidos, foram realizadas 600 determinações ao acaso com o auxílio de contador de laboratório, conforme proposto por Marchiori (1980). A freqüência de poros foi obtida de forma indireta, a partir de um quadrado de área conhecida superposto a fotomicrografias de seção transversal da madeira. As medições foram realizadas em microscópio Carl Zeiss, com ocular de escala graduada, no Laboratório de Anatomia da Madeira da Universidade Federal de Santa Maria. Nas características quantitativas, os números entre parênteses equivalem aos valores mínimos e máximos observados. O valor que acompanha a média é o desvio padrão. As fotomicrografias foram tomadas em microscópio Olympus cx40, equipado com câmera digital Olympus Camedia c3000. 


\section{DESCRIÇÃO ANATÔMICA}

Madeira de porosidade difusa. Anéis de crescimento distintos, delimitados por estreita camada de fibras com diâmetro radial reduzido e, por vezes, pela maior concentração de poros no lenho inicial.

Vasos numerosos a muito numerosos $(49 \pm 7,1$ (37 - 62) poros $/ \mathrm{mm}^{2}$ ), ocupando $9,5 \pm 2,1 \%$ do volume da madeira. Poros predominantemente solitários: múltiplos radiais de $2-4$ (7), pouco frequientes, e localizados principalmente no início do anel de crescimento. Vasos de seção circular a oval, por vezes ligeiramente poligonais, muito pequenos $(42,8 \pm 12(17,5-85) \mu \mathrm{m}) \mathrm{e}$ de paredes espessas $(3,0 \pm 0,64(1,2-5,0) \mu \mathrm{m})$. Elementos vasculares longos $(809,4 \pm 152,1$ $(460-1100) \mu \mathrm{m})$, com placas de perfuração simples, oblíquas ou verticais, dotados de apêndices em ambas as extremidades. Pontoações intervasculares alternas, circulares $(4,5 \pm 0,49$ $(3,6-5,1) \mu \mathrm{m})$; abertura em fenda inclusa, ornamentada, ao menos em parte dos vasos. Pontoações raio-vasculares com aréolas distintas, semelhantes às intervasculares, embora menores $(3,1 \pm 0,11(2,5-3,1) \mu \mathrm{m})$ e restritas às margens de raios. Espessamentos espiralados e conteúdos, ausentes.

Parênquima axial muito distinto das fibras, representando $22,7 \pm 3,6 \%$ do volume da madeira; nos padrões paratraqueal escasso, apotraqueal difuso e, principalmente, difuso-emagregados. Séries parenquimáticas compostas de $4-8$, menos frequentemente, $2-9$ células, medindo 763,6 $\pm 206,5(240-1180) \mu \mathrm{m}$ de altura. Cristais prismáticos solitários ou em séries de até 3 unidades, escassos a abundantes, presentes em câmaras ou em células de parênquima axial, maiores do que as adjacentes.

Raios muito numerosos $(16 \pm 2,72(12-22)$ raios $/ \mathrm{mm}$ ), ocupando $21,1 \pm 3,5 \%$ do volume da madeira; heterogêneos, reúnem células procumbentes na parte multisseriada e $1-10$, mais frequentemente $2-4$ fileiras marginais de células quadradas e, principalmente, eretas, raro com células procumbentes maiores do que as do corpo. Raios muito estreitos, com 1 - 2 (raro $3)$ células de largura. Raios multisseriados com 4-20, mais comumente 5 - 11 células de altu$\mathrm{ra}$, medindo $360 \pm 146,6(150-780) \mu \mathrm{m}$; a parte multisseriada, relativamente curta, é geralmente menor do que as margens unisseriadas e de largura semelhante. Devido à frequente fusão axial, os raios multisseriados incluem, na maioria das vezes, mais de uma parte multisseriada. Raios unisseriados com 1 - 5 (9) células de altura, medindo $221,2 \pm 87,8$ (60 430) $\mu \mathrm{m}$. Células radiais de paredes disjuntas, presentes. Inclusões minerais, células envolventes, células perfuradas e conteúdos, ausentes.

Fibras de pontoações areoladas e aberturas cruzadas, presentes nas faces radiais e tangenciais da parede. Tecido fibroso representando 47,8 $\pm 5,3 \%$ do volume da madeira. Fibras de comprimento médio ( $1570 \pm 233,6$ (1030 $-2020) \mu \mathrm{m}), \operatorname{com} 21,9 \pm 2,1(17,5-25) \mu \mathrm{m} \mathrm{de}$ largura e de paredes finas a espessas $(6,5 \pm 0,93$ $(5,0-8,7) \mu \mathrm{m})$. Fibras septadas, fibras gelatinosas e espessamentos espiralados, ausentes. Traqueídeos vasicêntricos, presentes.

Outros caracteres: Variantes cambiais, tubos laticíferos e taniníferos, canais intercelulares, células oleíferas ou mucilaginosas e estratificação, ausentes. Máculas medulares, ocasionais.

\section{ANÁLISE DA ESTRUTURA ANATÔMICA}

A maior parte das características anatômicas observadas na madeira de Psidium cattleianum está de acordo com as possibilidades estruturais atribuídas à família Myrtaceae e ao gênero Psidium (Record \& Hess, 1949; Metcalfe \& Chalk, 1972), salientando-se a presença de poros predominantemente solitários, de placas de perfuração simples, de pontoações intervasculares alternas e ornamentadas, de parênquima apotraqueal difuso-em-agregados, de raios heterogêneos estreitos, de fibras com pontoações areoladas e comprimento médio, e de traqueídeos vasicêntricos. A frequiência de raios (16/ 

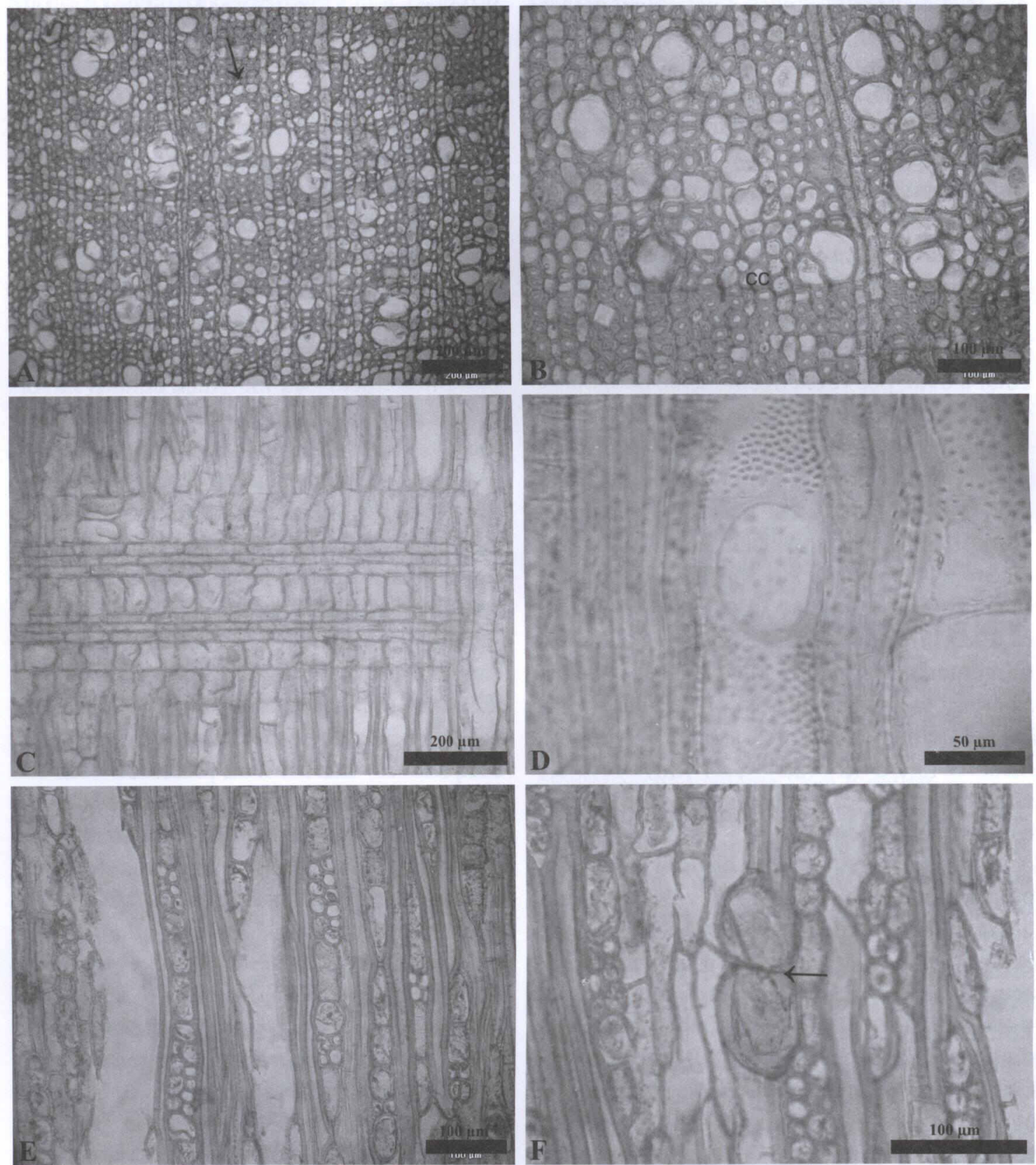

FIGURA 1 - Fotomicrografias da madeira de Psidium cattleianum. A - Porosidade difusa, poros solitários, em curtos múltiplos radiais, e parênquima apotraqueal difuso-em-agregados (seta), em seção transversal. B - Mesma seção, com maior aumento, destacando um limite de anel de crescimento (cc), poros de seção circular a oval e células de parênquima axial. C - Aspecto geral de raio heterogêneo axialmente fusionado, com células procumbentes, no corpo, e margens de células eretas e quadradas (seção longitudinal radial). D - Detalhe de vaso com placa de perfuração simples, em vista radial. E - Raios estreitos e frequentemente fusionados, em seção longitudinal tangencial. F - Mesma seção, com maior aumento; cristais prismáticos em curta série, no parênquima axial (seta). 
$\mathrm{mm}$ ) presentemente observada, todavia, resulta superior ao referido para o gênero $(13 / \mathrm{mm})$, em valores médios.

Com relação à descrição de Souza (2000), no material em estudo foram observadas diferenças apenas no tocante à frequiência e diâmetro de poros, bem como na presença de células perfuradas em raios, caráter não confirmado na presente investigação. Cabe salientar que características quantitativas, especialmente de elementos vasculares, são muito influenciadas pela idade da árvore e ambiente (Carlquist, 1975; Baas et al., 1983; Lindorf, 1994), podendo explicar as discrepâncias observadas. A respeito das células perfuradas, a presença escassa do caráter reduz seu valor diagnóstico (IAWA Committee, 1989).

$\mathrm{Na}$ estrutura anatômica de Psidium cattleianum, merecem destaque o comprimento de elementos vasculares $(809 \mu \mathrm{m})$ e de fibras $(1570 \mu \mathrm{m})$, superiores ao comumente observado em espécies nativas da família (400 600 e $700-1200 \mu \mathrm{m}$, respectivamente), bem como a presença de poros em múltiplos radiais e de cristais solitários ou em curtas séries (até 3 unidades) no parênquima axial, características igualmente distintas do observado na maioria das espécies sul-rio-grandenses. Considerandose o arranjo de poros, por exemplo, apenas Eugenia mansoi, Plinia rivularis e Myrciaria tenella seguem o padrão descrito em Psidium cattleianum.

Outro aspecto importante no material em estudo, diz respeito às características dos raios. De acordo com Ragonese (1977), raios estreitos e axialmente fusionados, de corpo multisseriado relativamente baixo e composto por poucas células, são comuns em Myrtaceae. Os resultados do presente estudo corroboram esta interpretação. A abundância de raios axialmente fusionados, no entanto, parece peculiar à espécie investigada, diferentemente de outras Mirtáceas nativas relacionadas na literatura, pois, embora também presente, o caráter é de ocorrência escassa. Este traço anatômico, a exemplo dos anteriormente mencionados, pode ser útil para a identificação da espécie.

\section{REFERÊNCIAS BIBLIOGRÁFICAS}

BAAS, P.; WERKER, E.; FAHN, A. Some ecological trends in vessel characters. IAWA Bulletin, v.4, n. 2-3, p. 141-160, 1983.

BURGER, L. M.; RICHTER, H. G. Anatomia da Madeira. São Paulo: Ed. Nobel, 1991. 154 p.

CARLQUIST, S. Ecological strategies of xylem evolution. Berkeley: University of California Press, $1975.259 \mathrm{p}$.

DUJARDIN, E. P. Eine neue Holz-Zellulosenfaerbung. Mikrokosmos, n. 53, p. 94, 1964.

IAWA COMMITTEE. IAWA list of microscopic features for hardwood identification. IAWA Bulletin, v.10, n. 3, p. 218-359, 1989.

LINDORF, H. Eco-anatomical wood features of species from a very dry tropical forest. IAWA Bulletin, v.15, n. 4, p. 361-376, 1994.

MARCHIORI, J. N. C. Estudo anatômico do xilema secundário de algumas espécies dos gêneros Acacia e Mimosa, nativas no Estado do Rio Grande do Sul. 1980. 186f. Dissertação (Mestrado em Engenharia Florestal) - Universidade Federal do Paraná, Curitiba, 1980.

MARCHIORI, J. N. C.; SOBRAL, M. Dendrologia das Angiospermas: Myrtales. Santa Maria: Editora UFSM, 1997. 304 p.

METCALFE, C. R.; CHALK, L. Anatomy of the Dicotyledons. Oxford: Clarendon Press, 1972. $1500 \mathrm{p}$.

RECORD, S. J.; HESS, R. W. Timbers of the New World. New Haven: Yale University Press, 1949. $640 \mathrm{p}$.

RAGONESE, A. M. Caracteres anatómicos del parénquima radial y axial en leño de las Mirtáceas. Darwiniana, v. 21, n. 1, p. 27-41, 1977.

SOUZA, L. P. Anatomia ecológica do lenho de Psidium cattleianum Sabine (Myrtaceae) e sua relação com a morfologia foliar e a cor dos frutos. 2000. 76f. Dissertação (Mestrado em Botânica) - Universidade Federal do Paraná, Curitiba, 2000.

SOBRAL, M. A família Myrtaceae no Rio Grande do Sul. São Leopoldo: Unisinos, 2003. 215 p. 